\title{
Factitious Disorder
}

National Cancer Institute

\section{Source}

National Cancer Institute. Factitious Disorder. NCI Thesaurus. Code C92198.

A category of psychiatric disorders which are characterized by physical or psychological symptoms that are intentionally produced in order to assume the sick role; there is no external incentive for the behavior, such as economic gain or avoiding legal responsibility, and the person is unaware of any self-motivating factors. 